\title{
Chronically gorging $v$. nibbling fat and cholesterol increases postprandial lipaemia and atheroma deposition in the New Zealand White rabbit
}

\author{
Christine Juhel, Yan Pafumi, Michele Senft, Huguette Lafont and Denis Lairon* \\ Unit 476-INSERM (Institut National de la Santé et de la Recherche Médicale), 18 avenue Mozart, 13009 Marseille, France
}

(Received 2 November 1998 - Revised 5 August 1999 - Accepted 12 October 1999)

\begin{abstract}
In the present study, we compared the effects of nibbling and gorging on postprandial lipaemia and lipoproteins, hepatic lipid uptake and atheroma deposition. New Zealand White rabbits were fed on a low-fat (LF) control diet or a peanut oil- ( $10 \mathrm{~g} / \mathrm{d})$ and cholesterol- $(0.5 \mathrm{~g} / \mathrm{d})$ enriched (HF) diet with the fat and cholesterol components given either by nibbling (HF-N) or gorging (HF-G). After 4 and 8 weeks, rabbits were given a test meal, which was either nibbled or taken as a bolus. The LF diet did not noticeably alter postprantial lipid variables. Triacylglycerol levels, $0-35 \mathrm{~h}$ lipid responses and plasma accumulation of dietary lipids were significantly higher in the HF-G group than in the HF-N group, despite higher post-heparin plasma lipase activities. Furthermore, as studied on cultured isolated hepatocytes, the higher the rate of supply of triacylglycerol- and cholesterol-rich lipoproteins (TCRL), the lower the rate of lipid uptake and bile salt secretion. Atheroma deposition was significantly increased by gorging the HF diet and was correlated with levels of most postprandial lipid variables. We conclude that gorging $v$. nibbling a fat and cholesterol-enriched diet exacerbates postprandial lipaemia by reducing the rate of TCRL clearance and favours atheroma deposition.
\end{abstract}

Dietary lipids: Hepatic lipid uptake: Lipoproteins

The importance of changes in plasma lipids and lipoproteins occurring in the postprandial state, as suggested by Zilversmit (1979), has gained increasing attention during the last decade (Tall et al. 1982; Cohen et al. 1988; Cohn et al. 1988; Karpe et al. 1993; Lairon, 1996; Bergeron \& Havel, 1997). In fact, several human studies have already provided evidence that altered postprandial lipid and lipoprotein patterns are associated with atheroma plaque progression and CHD (Weintraub et al. 1987; Groot et al. 1991; Miesenböck \& Patsch, 1992). Triacylglycerol-rich lipoprotein remnants, either of hepatic or intestinal origin, have been implicated in this process (Patsch et al. 1992; Karpe et al. 1993).

The detrimental effects of increasing the amounts of saturated fat and cholesterol in the diet on post-absorptive plasma- and LDL-cholesterol levels and the risk of CHD have been extensively documented (Gardner \& Kraemer, 1996). More recently, the acute effects of the amount of ingested dietary triacylglycerols (Murphy et al. 1995; Dubois et al. 1998) or cholesterol (Dubois et al. 1994) on the postprandial responses have been reported in human subjects. A few studies regarding the influence of meal frequency on fasting lipid and lipoprotein levels (Jenkins et al. 1989, 1992; Arnold et al. 1993; McGrath \& Gibney, 1994; Mann, 1997) have reported that increasing meal frequency attenuates the postprandial response to a daily prudent diet, improves post-absorptive lipid variables and especially lowers LDL-cholesterol, during studies performed in healthy or non-insulin-dependent diabetic subjects. Nevertheless, the long-term consequences of the acute metabolic changes induced by nibbling $v$. gorging have not been evaluated.

Taken together, these observations raised the important question of the link between the amount of dietary lipids ingested during the daytime, the resulting postprandial response and finally, the potential atherogenicity of the repetition of such metabolic events.

To investigate this point, we selected the rabbit model because of its acknowledged use in nutrition and lipid metabolism research and its ability to develop measurable atheroma deposition within a few months of exposure to a lipid-rich diet (Bocan et al. 1993; Daley et al. 1994a,b). It should be emphasized that the rabbit is a spontaneous nibbler. In a previous study (Juhel et al. 1997), we observed that rabbits fed on a regular low-fat diet showed a negligible postprandial response to a bolus test meal but exhibited an exacerbated response to a bolus meal when given a high-fat, high-cholesterol diet for a sufficient period. In fact, only a limited number of postprandial studies have been reported in the rabbit (Van Heek \& Zilversmit, 1990; Juhel et al. 


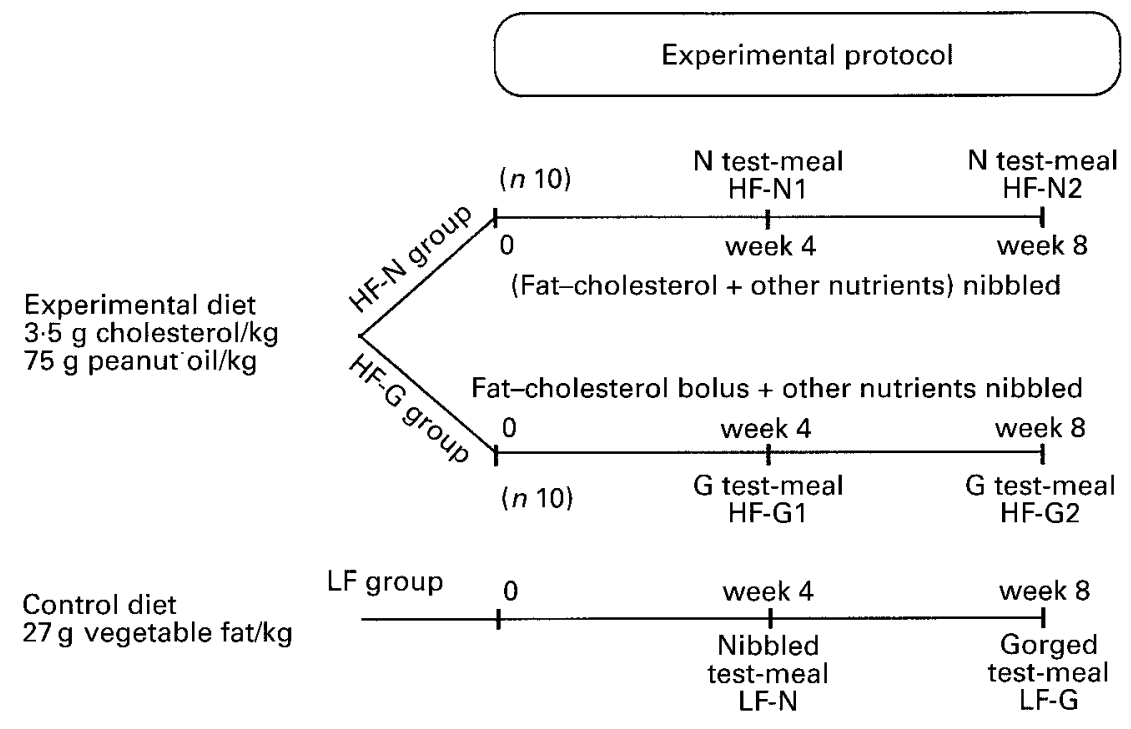

Fig. 1. Experimental protocol. The LF group $(n 8)$ was fed on the low-fat control diet and the HF-N $(n 10)$ and HF-G $(n 10)$ groups were fed on the fat $(10 \mathrm{~g} / \mathrm{d})$ and cholesterol $(0.5 \mathrm{~g} / \mathrm{d})$ parts of the diet by nibbling exclusively or gorging fat and cholesterol and nibbling most other nutrients respectively. The nibbled test meals were ingested over $3-4 \mathrm{~h}$. The gorged test meals were administered as a single bolus within $20 \mathrm{~min}$.

1997) which indicate that this species is characterized by a long postprandial hypertriacylglycerolaemic response lasting 20-30 h after ingestion of a bolus fat meal. We recently documented that the well-known high ability to develop atheroma in this species could result from this protracted hyperlipidaemic postprandial state (Juhel et al. 1997).

In the present study, using the rabbit model, we aimed to modulate the postprandial lipid response by spreading the daily lipid and cholesterol intake or giving it as a bolus.

\section{Materials and methods}

\section{Animals and diets}

Twenty-seven male New Zealand White rabbits (Elevage Scientifique des Dombes, Romans, France), 14-15 weeks old and weighing 2.71 (SE 0.05$) \mathrm{kg}$ at the beginning of the experiment were used. They were housed individually at $20^{\circ}$ and had free access to water and food. They were exposed to a $12 \mathrm{~h}$ light-dark cycle. The rabbits were randomly assigned to three groups (Fig. 1) and the overall protocol lasted 8 weeks. A group of seven rabbits was fed on $150 \mathrm{~g} / \mathrm{d}$ of a commercial low-fat (LF) $(27 \mathrm{~g} / \mathrm{kg})$, cholesterolfree diet in granular form (Usine d'Alimentation Rationnelle, Villemoison-Sur-Orge, France) for 8 weeks. Two groups of ten rabbits were fed on a high-fat $(\mathrm{HF})$, high-cholesterol diet providing $10 \mathrm{~g}$ peanut oil/d and $0.5 \mathrm{~g}$ cholesterol/d prepared by Usine d'Alimentation Rationnelle. The detailed nutrient composition of the diets is given in Table 1. As shown in Fig. 1, the HF-N group ( $n$ 10) nibbled $135 \mathrm{~g}$ mixed HF diet in granular form over $24 \mathrm{~h}$. The HF-G group ( $n$ 10) ingested most of the diet during $24 \mathrm{~h}$ except the daily dose of cholesterol and peanut oil which was ingested once daily (within $20 \mathrm{~min}$ ) in the form of an intrabuccal bolus given by using a $50 \mathrm{ml}$ syringe in a restraining cage. Rabbits were trained to receive boluses for several days and were not stressed by this treatment. There was no difference in the daily amounts of peanut oil $(10 \mathrm{~g})$ and cholesterol $(0.5 \mathrm{~g})$ ingested by $\mathrm{HF}-\mathrm{N}$ and $\mathrm{HF}-\mathrm{G}$ rabbits. $\mathrm{LF}$ and $\mathrm{HF}$ diets provided 220 and $240 \mathrm{~kJ} / \mathrm{kg}$ respectively. Weight gains were comparable in the three groups, i.e. 10.5 (SE 1.7), $12 \cdot 1$ (SE 2.0) and 11.9 (SE 1.8) g/d for rabbits in groups LF, HF-G and HF-N, respectively. Seven rabbits from the HF-N or HF-G groups were given test meals while three rabbits from each group were used for collecting hepatocytes.

\section{Test meals}

On the morning of the experiment day (weeks 4 and 8), after an overnight fast, the rabbits of the three experimental groups were given a test meal $(55 \mathrm{~g})$ of fixed composition as either an intrabuccal bolus given with a syringe within

Table 1. Nutrient content of experimental diets $(g / d)^{\star}$

\begin{tabular}{lccrc}
\hline Nutrient (g/d) & $\begin{array}{c}\text { LF diet } \\
\text { (nibbling) }\end{array}$ & $\begin{array}{c}\text { HF-N diet } \\
\text { (nibbling) }\end{array}$ & $\begin{array}{c}\text { HF-G diet } \\
\text { (gorging) }\end{array}$ \\
\hline Protein & 19.50 & 15.60 & $3.90(11.70)$ \\
Cellulose & 24.00 & 19.20 & $6.25(12.95)$ \\
Carbohydrate & 74.20 & 59.30 & $14.75(44.55)$ \\
Mineral-vitamin mixture† & 12.00 & 9.60 & 2.40 & $(7.20)$ \\
Vegetable fat & 4.50 & 3.60 & \multicolumn{2}{c}{$(2.70)$} \\
Peanut oil & - & 10.00 & 10.00 & \\
Cholesterol & - & 0.50 & 0.50 & \\
Water & 15.75 & 12.50 & 16.25 & $(9.45)$
\end{tabular}

LF, low fat; HF, high-fat; N, nibbled; G, gorged.

* The LF diet was a regular low-fat, cholesterol-free diet; HF-N and HF-G diets were comparable in terms of fat and cholesterol. Nibbling indicates that rabbits nibbled their diet during the whole day. Gorging indicates that rabbits received one part of the diet (including the daily amounts of peanut oil and cholesterol) as an intrabuccal bolus within 20 min and the remaining part in granular form (parenthesis values) during the rest of the day. †UAR-205 (UAR, Villemoison sur Orge, France). 
$20 \mathrm{~min}$ or a granular feed which was nibbled within $3-4 \mathrm{~h}$. As described in Fig. 1, the LF rabbits received a nibbled test meal (LF-N, $n$ 7) on week 4 and another one as a bolus (LF-G) on week 8. Giving either the nibbled or the gorged test meal to LF rabbits allowed us to compare the acute effects of nibbling and gorging. On weeks 4 and 8 , the HF-G group ( $n$ 7) received test meals as bolus only (HF-G1 and HF-G2) whereas the HF-N $(n 7)$ rabbits had nibbled test meals only (HF-N1 and HF-N2). The test meals were prepared as follows: cholesterol $(0 \cdot 5 \mathrm{~g}),\left[{ }^{3} \mathrm{H}\right]$ cholesterol $(1480 \mathrm{kBq} / \mathrm{g}$ cholesterol) and $\left[{ }^{14} \mathrm{C}\right]$ triolein $(74 \mathrm{kBq} / \mathrm{g}$ peanut oil) $(\mathrm{CEA}$, Gif-sur-Yvette, France) were dissolved in chloroformmethanol $(2: 1, \mathrm{v} / \mathrm{v})$. Phospholipids $(0.5 \mathrm{~g})$ and peanut oil $(10.0 \mathrm{~g})$ were added after the organic solvent was evaporated to dryness under $\mathrm{N}_{2}$. Then, casein $(4.0 \mathrm{~g})$, cellulose $(5.0 \mathrm{~g})$, carbohydrates $(15.5 \mathrm{~g})$, mineral and vitamin mixture $(2.8 \mathrm{~g})$ and water $(18.2 \mathrm{~g})$ were added and blended. During the $35 \mathrm{~h}$ follow-up, rabbits had free access to water.

\section{Analytical determinations}

Blood was collected from the ear artery in tubes containing lithium-heparin. Blood samples were obtained either in the post-absorptive state (after an overnight fast) every 2 weeks or $10,20,25$ and $35 \mathrm{~h}$ postprandially, after test-meal presentation in line with previous studies (Van Heek \& Zilversmit, 1990; Juhel et al. 1997). In order adequately to store plasma samples, a cocktail of inhibitors was added as reported (Cardin et al. 1984). Blood was centrifuged for $15 \mathrm{~min}$ at $910 \mathrm{~g}$ at room temperature.

Plasma lipid variables. Triacylglycerols were determined by an enzymic procedure (Buccolo \& David, 1973) using commercial kits (Kits BioMérieux, Marcy l'Etoile, France). Total and free cholesterol components were assayed by the cholesterol oxidase method (Siedel et al. 1983) with kits purchased from BioMérieux. Plasma phospholipids were assayed by an enzymic procedure (Takayama et al. 1977) with commercial kits (BioMérieux). Labelled dietary and plasma lipids were measured by dual scintillation counting with Packard 1600TR equipment (Packard, Meriden, CT, USA) with an external standard for quench correction.

Lipoproteins. Plasma $(1 \mathrm{ml}$; overnight post-absorptive or $20 \mathrm{~h}$ postprandial peak samples) was used for separation of lipoprotein fractions, i.e. triacylglycerol and cholesterolrich lipoproteins $($ TCRL) $=$ chylomicrons + VLDL + IDL $(\mathrm{d} \leq 1.019 \mathrm{~kg} / \mathrm{l})$, LDL $(1.019 \leq \mathrm{d} \leq 1.063 \mathrm{~kg} / \mathrm{l})$ and HDL $(1.063 \leq \mathrm{d} \leq 1.21 \mathrm{~kg} / \mathrm{l})$ by ultracentrifugation on a $\mathrm{KBr}$ discontinuous gradient $\left(200000 \mathrm{~g}\right.$ for $24 \mathrm{~h}$ at $15^{\circ}$ in a Beckman ultracentrifuge (SW 40Ti rotor; Beckman, Palo Alto, CA, USA) as previously described (Juhel et al. 1997). Lipoprotein lipids were adjusted for recovery, i.e. triacylglycerols (94 (SE 5) \%), esterified cholesterol (88 (SE 5) \%), free cholesterol (92 (SE 8) \%), phospholipids (79 (SE 2) \%).

Lipoprotein lipase and hepatic lipase activities. On weeks 4 and 8 , at the end point ( $35 \mathrm{~h}$ postprandially) of the test-meal follow-up, post-heparin plasma lipoprotein lipase and hepatic lipase activities were measured as previously described (Van Heek \& Zilversmit, 1990; Juhel et al. 1997). Briefly, blood was collected from the marginal ear artery $20 \mathrm{~min}$ after a single injection of $200 \mathrm{IU}$ heparin $/ \mathrm{kg}$
(Heparine LEO, Paris, France). Lipoprotein lipase activity was calculated by subtracting hepatic lipase activity from total lipase activity and expressed as $\mu \mathrm{mol}$ free fatty acids $/ \mathrm{ml}$ per min (Juhel et al. 1997).

Liver lipids. On week 8, just after killing of the rabbits, the liver was excised, rinsed with $0 \cdot 15 \mathrm{M}-\mathrm{NaCl}$, frozen and then kept at $-20^{\circ}$ until analysis. Liver lipids were extracted and then quantified as previously described (Juhel et al. 1997).

\section{Postprandial triacylglycerol- and cholesterol-rich lipoprotein uptake by cultured rabbit hepatocytes}

Isolation and culturing of liver cells. On week 4, three rabbits from each experimental group (HF-N and HF-G) were killed. Rabbit hepatocytes were prepared by perfusion of a liver lobe with collagenase $(0.005 \mathrm{~g} / \mathrm{l})$ as described previously (Whiting et al. 1989). After isolation and washing, the cells were suspended in William's medium E supplemented with fetal calf serum $(100 \mathrm{ml} / \mathrm{l})$, glutamine $(0.1 \mathrm{mg} / \mathrm{ml})$, kanamycin $(0.1 \mathrm{mg} / \mathrm{ml})$, penicillin $(20$ units $/ \mathrm{ml})$, streptomycin $(0.1 \mathrm{mg} / \mathrm{ml})$ and seeded on collagen-coated dishes $\left(1 \times 10^{5}\right.$ cells $\left./ \mathrm{cm}^{2}\right)$. The dishes were incubated at $37^{\circ}$ in an atmosphere containing $\mathrm{CO}_{2}(50 \mathrm{ml} / \mathrm{l})$ for $2-3 \mathrm{~h}$. The medium was removed by aspiration and the cell monolayers washed with William's medium E supplemented as described earlier but without fetal calf serum. Experimental additions to the culture medium were made $24 \mathrm{~h}$ after this point and represented time zero.

Characterization of postprandial triacylglycerol- and cholesterol-rich lipoprotein fractions. TCRL is the $\mathrm{d} \leq$ $1.019 \mathrm{~kg} / \mathrm{l}$ fraction as described earlier. TCRL used for the cell culture experiments were isolated from HF-N and HF-G rabbit plasmas $20 \mathrm{~h}$ after test-meal consumption performed on week 4. The postprandial TCRL fractions isolated from HF-N and HF-G rabbits were called, for clarity, TCRL-N and TCRL-G respectively. The lipid compositions of TCRL-N and TCRL-G were not different. TCRL-N and TCRL-G contained (g/100 g): 11.3 (SE 1.7) v. 17.5 (SE 1.6) triacylglycerols, 22.5 (SE 0.9) v. 15.5 (SE 1.1) free cholesterol, 54.4 (SE 2.1) v. 53.5 (SE 4.0) esterified cholesterol and 12.8 (SE 0.4) v. 13.4 (SE 0.7) phospholipids. TCRL-N and TCRL-G total cholesterol concentrations were adjusted to $31 \mathrm{mmol} / \mathrm{l}$ with $0 \cdot 15 \mathrm{M}-\mathrm{NaCl}$. This value was chosen to get a final total cholesterol concentration in dishes comparable to the TCRL postprandial increment in rabbit plasma. TCRL were dialysed at $4^{\circ}$ against culture medium and filtered through $0.22 \mu \mathrm{m}$ membranes, before addition to hepatocyte cultures.

Incubation of cultured liver cells with TCRL. To mimic in vivo situations, the total amount of TCRL was added to the liver cell medium either once at time zero (gorging) or stepwise, i.e. $0 \cdot 25$ of the TCRL dose at time zero and then $0 \cdot 25$ dose at 1,2 and $3 \mathrm{~h}$ (nibbling). At 4, 8, 12 and $20 \mathrm{~h}$ after the beginning of the experiment, $0.8 \mathrm{ml}$ culture cell medium was collected in order to measure remaining amounts of TCRL radiolabelled lipids, total cholesterol and triacylglycerols. The liver cell viability was controlled (by checking luminescence using an optical microscope) in every dish during the experiment and estimated at about $90 \%$. At the end point $(20 \mathrm{~h})$, total bile acid content in the 
culture medium was assayed by an established enzymic method (Domingo et al. 1972).

\section{Atheroma plaque quantification}

Immediately after killing (week 8), the arteries were carefully isolated from the arch of aorta to the iliac section. Lipids were removed on the external side of the aortas. Aortas were cut in the longitudinal axis, fixed in $100 \mathrm{ml} / \mathrm{l}$ formol overnight and stained for $20 \mathrm{~min}$ in red sudan IV as previously described (Holman et al. 1958). Total, arch, thoracic and abdominal aorta surfaces covered by stained atherosclerotic lesions were quantified by using video densitometry and a BioLab software package as before (Juhel et al. 1997).

\section{Statistical analysis}

The statistical significance $(P<0.05)$ of the differences observed between the three groups of rabbits was assessed by using ANOVA for factorial non-repeated values and the Fisher test (Winer, 1971). In a given group of rabbits, the statistical significance $(P<0 \cdot 05)$ of the differences observed between the experimental meals (individual time points or areas under the curves (AUC)) or post-absorptive values were assessed by using ANOVA for repeated values and the Fisher test. Linear regression analyses were performed. The Stat-View II (Abacus Concepts Inc., Berkeley, CA, USA) micro-computer program was used.

\section{Results}

\section{Post-absorptive plasma lipids and lipoproteins}

As shown in Fig. 2, $18 \mathrm{~h}$ overnight post-absorptive plasma concentrations of triacylglycerols and total cholesterol measured in the rabbits fed on the LF diet remained unchanged throughout the 8 weeks nibbling. Conversely, in the two groups of rabbits chronically ingesting the HF diet, rapid and important changes were observed. After 2 weeks, the rabbits on the gorging diet (HF-G) showed significantly increased triacylglycerol levels which still increased markedly after 8 weeks $(5 \cdot 27$ (SE $1 \cdot 15)$ mmol/l). The rabbits on the nibbled diet (HF-N) maintained low triacylglycerol levels comparable to those of rabbits on the LF diet for 6 weeks which increased slightly after 8 weeks (0.91 (SE 0.24) $\mathrm{mmol} / \mathrm{l})$.

At the same time, plasma cholesterol levels increased in a stepwise fashion over time of feeding the HF diet as compared with the LF diet. After 8 weeks, post-absorptive plasma cholesterol levels were 1.6-fold higher in rabbits on HF-G (26.4 (SE 3.5) v. 14.8 (SE 5.8) mmol/l) than in those on HF-N. Overall changes in the two groups of rabbits were related to marked changes in cholesterol ester concentrations.

The post-absorptive lipoprotein lipid values are given in Table 2. After feeding the HF diet for 4 weeks and more markedly for 8 weeks, triacylglycerols in TCRL increased dramatically in rabbits receiving HF-G and only slightly but significantly in those receiving HF-N. Concentrations of phospholipids and total cholesterol in TCRL showed somewhat comparable values but with less marked differences
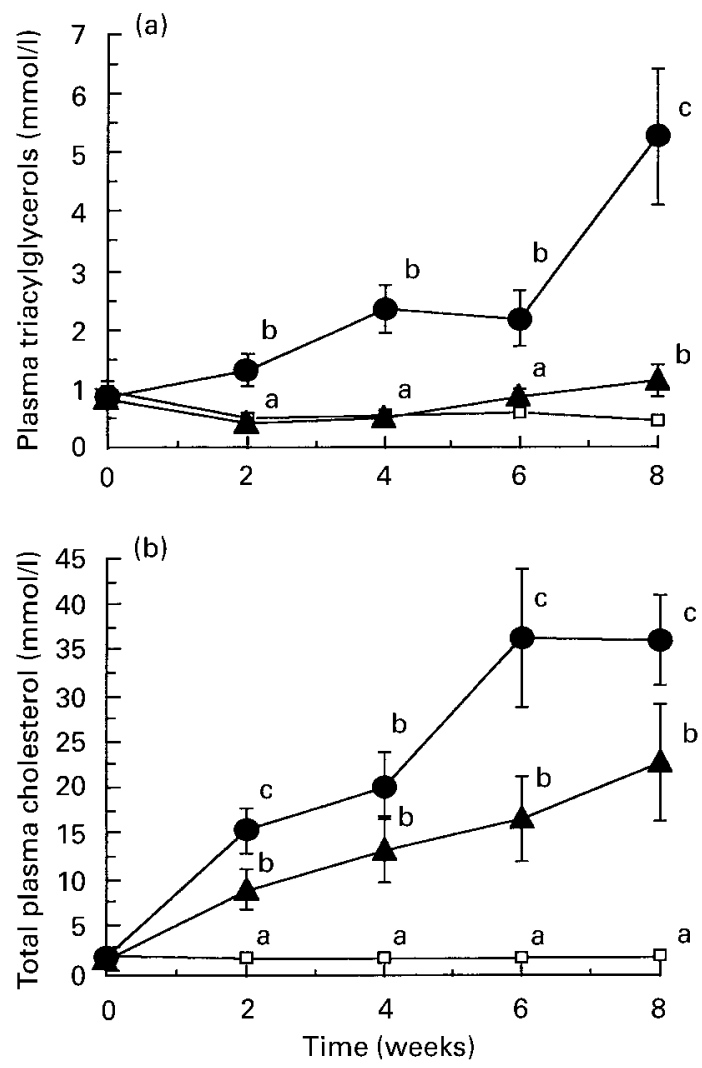

Fig. 2. Post-absorptive concentrations of (a) plasma triacylglycerols and (b) total plasma cholesterol in rabbits fed on a low-fat diet ( $\square$ ) or fed on a high-fat, high-cholesterol diet with the fat and cholesterol components ingested by nibbling $(\boldsymbol{\Lambda})$ or gorging $(\boldsymbol{\bullet})$ for 8 weeks. Values are means for seven rabbits, with their standard errors represented by vertical bars. ${ }^{a, b, c}$ Mean values at a given time point not sharing a common letter were significantly different: $P<0.05$ (ANOVA for factorial non-repeated values and Fisher's test).

between HF-G and HF-N groups. Post-absorptive LDL- as well as HDL-triacylglycerol concentrations increased more markedly in the HF-G group than in HF-N after 4 and 8 weeks while comparable concentrations in phospholipids and total cholesterol were observed in LDL and HDL fractions in both groups.

\section{Postprandial plasma lipids and lipoproteins}

As shown in Fig. 3 ( $a$ and b), the relative changes in plasma triacylglycerol levels for $35 \mathrm{~h}$ postprandially after the bolus or the nibbled test-meals in rabbits fed on LF were comparably low. Conversely, a higher rise in triacylglycerols was observed postprandially in the HF-N group after 4 and 8 weeks and even more markedly, in the HF-G group.

In rabbits given LF, the postprandial relative changes in plasma esterified and free cholesterol (Fig. 3 (c, d, e and f)) were comparably low after the bolus or nibbled test meals. Small postprandial changes were also observed postprandially in the HF-N group whereas significantly higher free and esterified cholesterol concentrations were observed in the HF-G group.

The $0-35 \mathrm{~h}$ AUC values, calculated by the trapezoidal method are presented in Fig. 4. Triacylglycerol 0-35 h AUC 
Table 2. Lipoprotein lipid levels $(\mathrm{mmol} / \mathrm{l})$ in post-absorptive $(0 \mathrm{~h})$ and postprandial $(20 \mathrm{~h})$ blood samples from rabbits given fat and cholesterol either by nibbling (HF-N) or gorging (HF-G) after 4 and 8 weeks on a high-fat, high-cholesterol diet $\dagger$

(Mean values with their standard errors for seven rabbits per group)

\begin{tabular}{|c|c|c|c|c|c|c|c|c|c|}
\hline & & \multicolumn{4}{|c|}{ Lipoprotein lipids after 4 weeks } & \multicolumn{4}{|c|}{ Lipoprotein lipids after 8 weeks } \\
\hline & & \multicolumn{2}{|c|}{ HF-N } & \multicolumn{2}{|c|}{ HF-G } & \multicolumn{2}{|c|}{$\mathrm{HF}-\mathrm{N}$} & \multicolumn{2}{|c|}{$\mathrm{HF}-\mathrm{G}$} \\
\hline & & Mean & SE & Mean & SE & Mean & SE & Mean & SE \\
\hline $\begin{array}{c}\text { Postabsorptive } \\
\text { TCRL } \ddagger 0 \mathrm{~h}\end{array}$ & $\begin{array}{l}\text { TG } \\
\text { TC } \\
\text { PL }\end{array}$ & $\begin{array}{l}0.29^{a} \\
8.89 \\
1.36^{a}\end{array}$ & $\begin{array}{l}0.08 \\
3.05 \\
0.43\end{array}$ & $\begin{array}{c}1.92^{b} \\
13.44 \\
2.58^{b}\end{array}$ & $\begin{array}{l}0.43 \\
2.55 \\
0.40\end{array}$ & $\begin{array}{r}0.49^{c} \\
16.91^{c} \\
2.93^{c}\end{array}$ & $\begin{array}{l}0.18 \\
6.63 \\
0.14\end{array}$ & $\begin{array}{r}4 \cdot 36^{d} \\
29 \cdot 37^{d} \\
4 \cdot 98^{d}\end{array}$ & $\begin{array}{l}1.39 \\
3.89 \\
0.21\end{array}$ \\
\hline LDL $0 \mathrm{~h}$ & $\begin{array}{l}\text { TG } \\
\mathrm{TC} \\
\mathrm{PL}\end{array}$ & $\begin{array}{l}0.11^{a} \\
3 \cdot 62 \\
0.64^{a}\end{array}$ & $\begin{array}{l}0.02 \\
0.69 \\
0.10\end{array}$ & $\begin{array}{l}0 \cdot 35^{b} \\
5 \cdot 62 \\
1 \cdot 15^{b}\end{array}$ & $\begin{array}{l}0.07 \\
2.01 \\
0.38\end{array}$ & $\begin{array}{l}0.17 \\
4.65 \\
0.69\end{array}$ & $\begin{array}{l}0.07 \\
0.74 \\
0.12\end{array}$ & $\begin{array}{l}0.37 \\
5.55 \\
0.79\end{array}$ & $\begin{array}{l}0.09 \\
1.81 \\
0.18\end{array}$ \\
\hline $\mathrm{HDL} \mathrm{Oh}$ & $\begin{array}{l}\text { TG } \\
\mathrm{TC} \\
\mathrm{PL}\end{array}$ & $\begin{array}{l}0.09^{a} \\
0.66 \\
0.36^{a}\end{array}$ & $\begin{array}{l}0.01 \\
0.11 \\
0.04\end{array}$ & $\begin{array}{l}0.43^{b} \\
1.09 \\
0.75^{b}\end{array}$ & $\begin{array}{l}0.07 \\
0.29 \\
0.11\end{array}$ & $\begin{array}{l}0.19^{c} \\
1.14 \\
0.42\end{array}$ & $\begin{array}{l}0.06 \\
0.19 \\
0.05\end{array}$ & $\begin{array}{l}0.39^{d} \\
1 \cdot 11 \\
0.49\end{array}$ & $\begin{array}{l}0.13 \\
0.23 \\
0.08\end{array}$ \\
\hline $\begin{array}{l}\text { Postprandial v } \\
\text { TCRL } \ddagger 20 \mathrm{~h}\end{array}$ & $\begin{array}{l}\text { TG } \\
\text { TC } \\
\text { PL }\end{array}$ & $\begin{array}{c}1.67^{\mathrm{a} *} \\
12 \cdot 17^{\mathrm{a}} \\
1.90^{\mathrm{a}}\end{array}$ & $\begin{array}{l}0.55 \\
3.23 \\
0.51\end{array}$ & $\begin{array}{c}4.75^{b *} \\
18.47^{b} \\
3.63^{b *}\end{array}$ & $\begin{array}{l}1.46 \\
2.89 \\
0.34\end{array}$ & $\begin{array}{r}2.5^{\mathrm{c} *} \\
21.17^{\mathrm{c}} \\
3.81^{\mathrm{c}}\end{array}$ & $\begin{array}{l}0.93 \\
6.92 \\
1.00\end{array}$ & $\begin{array}{c}6 \cdot 75^{d *} \\
35 \cdot 01^{d} \\
5 \cdot 86^{d}\end{array}$ & $\begin{array}{l}1.93 \\
3.76 \\
0.52\end{array}$ \\
\hline LDL $20 \mathrm{~h}$ & $\begin{array}{l}\text { TG } \\
\mathrm{TC} \\
\mathrm{PL}\end{array}$ & $\begin{array}{l}0.28 \\
1.99^{a *} \\
0.52^{a}\end{array}$ & $\begin{array}{l}0.05 \\
0.44 \\
0.08\end{array}$ & $\begin{array}{l}0.36 \\
3.54^{b} \\
0.75^{b}\end{array}$ & $\begin{array}{l}0.06 \\
1.57 \\
0.05\end{array}$ & $\begin{array}{l}0 \cdot 14^{c} \\
2 \cdot 13^{c} \\
0.41\end{array}$ & $\begin{array}{l}0.03 \\
0.56 \\
0.07\end{array}$ & $\begin{array}{l}0.41^{d_{*}} \\
4 \cdot 19^{d} \\
0.74\end{array}$ & $\begin{array}{l}0.11 \\
1.08 \\
0.31\end{array}$ \\
\hline $\mathrm{HDL} 20 \mathrm{~h}$ & $\begin{array}{l}\text { TG } \\
\text { TC } \\
\text { PL }\end{array}$ & $\begin{array}{l}0.25^{\star} \\
0.67^{a} \\
0.44\end{array}$ & $\begin{array}{l}0.05 \\
0.13 \\
0.06\end{array}$ & $\begin{array}{l}0.46 \\
0.96^{b} \\
0.44^{*}\end{array}$ & $\begin{array}{l}0.13 \\
0.16 \\
0.14\end{array}$ & $\begin{array}{l}0.20^{c} \\
0.84 \\
0.36\end{array}$ & $\begin{array}{l}0.03 \\
0.13 \\
0.03\end{array}$ & $\begin{array}{l}0.38^{d} \\
1.11 \\
0.47\end{array}$ & $\begin{array}{l}0.11 \\
0.13 \\
0.08\end{array}$ \\
\hline
\end{tabular}

TCRL, triacylglycerol- and cholesterol-rich lipoproteins; TG, triacylglycerol; TC, total cholesterol; PL, phospholipid.

${ }_{a, b}$ and ${ }^{c, d}$ Mean values within a row with different superscript letters were significantly different at $4\left({ }^{a, b}\right)$ and $8\left({ }^{c, d}\right.$ ) weeks: $P<0.05$ (ANOVA for factorial non-repeated values and Fisher's test at a probability of $95 \%$ ).

Mean values were significantly different from the corresponding post-absorptive $(0 \mathrm{~h})$ values: ${ }^{*} P<0.05$ (ANOVA for factorial repeated values and Fisher's test at a probability of $95 \%$ ).

†For details of diets and procedures, see Table 1 and pp. 550-551.

$\ddagger T C R L$ represents the $d<1.09 \mathrm{~g} / \mathrm{ml}$ fraction and includes chylomicrons, VLDL and $\beta$-VLDL particles.

(Fig. 4(a)) were markedly and significantly higher in the HF-G group than in the HF-N group after 4 and 8 weeks feeding. Total cholesterol 0-35 h AUC (Fig. 4(b)) were also significantly higher in the HF-G group than in HF-N and LF groups.

TCRL, LDL and HDL lipid values obtained at the postprandial peak $(20 \mathrm{~h})$ after the different test meals are given in Table 2. TCRL triacylglycerol concentrations were significantly higher postprandially over post-absorptive values in both groups. Postprandial TCRL lipid concentrations reached dramatically higher values in the HF-G group after 4 and 8 weeks whereas the HF-N group showed lower values, especially after 4 weeks. The postprandial increase in total TCRL-cholesterol was not statistically different between HF-G and HF-N groups. The LDL as well as the HDL lipid moieties did not show noticeable postprandial changes in either HF group.

\section{Postprandial accumulation of dietary lipids in plasma}

The addition of labelled esterified fatty acids and cholesterol to the test meals allowed the post-meal follow-up of plasma enrichments in lipids of dietary origin as illustrated in Figs. 4(d) and 4(e). A low accumulation of radiolabelled fatty acids was observed after the bolus or the nibbled test meals in the LF group while a slightly but significantly higher accumulation was observed in the HF-G group. A much more dramatic rise was shown by the HF-G group after 4 and 8 weeks feeding. The overall $0-35 \mathrm{~h}$ AUC of labelled fatty acid concentration (Fig. 4(d)) were 2.1- and 5.9-fold higher in HF-N and HF-G groups respectively, than in the LF group after 8 weeks. In HF-N and HF-G groups, the differences observed in the accumulation of labelled fatty acids in plasma were essentially due to those found in plasma- and TCRL-triacylglycerols (Table 2).

At the same time (Fig. 4(e)), the accumulation of labelled dietary cholesterol in plasma was low in the LF group after either test meal, whereas a marked accumulation of dietary cholesterol was observed postprandially in HF-N and HF-G group plasmas. The overall $0-35 \mathrm{~h}$ accumulations of dietary cholesterol in the plasma (Fig. 4(e)) were 6.9- and 8.5-fold higher in HF-N and HF-G groups respectively, than in the LF group after 8 weeks.

\section{Post-heparin plasma lipase activities}

Minimal levels of hepatic and lipoprotein lipase activities (1.5 (SE 0.2) and 7.5 (SE 0.9) $\mu \mathrm{mol}$ free fatty acids/h per ml respectively) were measured in the plasma of rabbits fed on LF. After 4 weeks feeding the HF diet no marked change was observed except a significant increase in hepatic lipase activity in the HF-G group only ( 1.9 fold). After 8 weeks, hepatic and lipoprotein lipase activities were significantly increased in the HF-N group (4.9 (SE 0.3) and 19.7 (SE 1.2) $\mu \mathrm{mol}$ free 

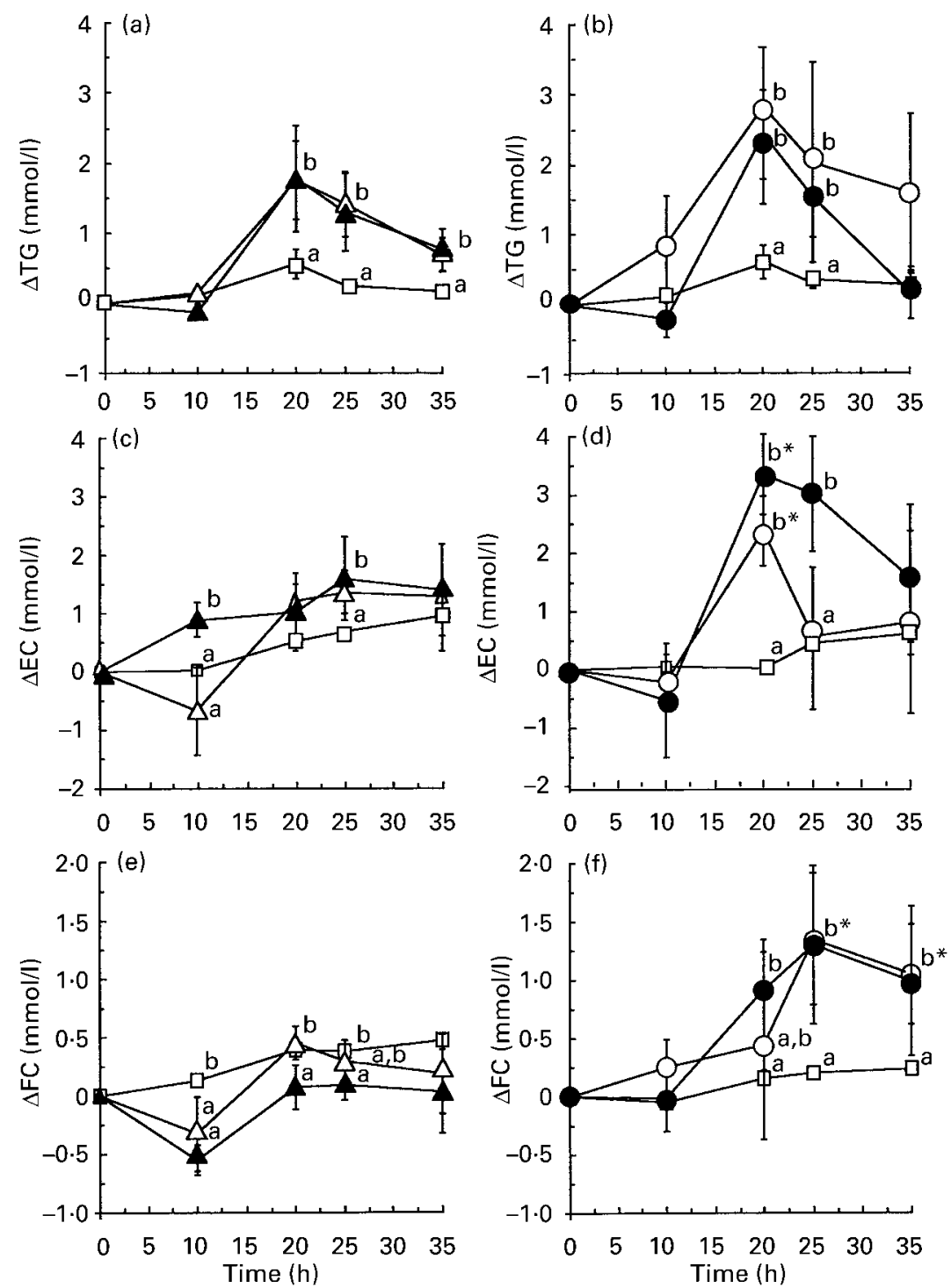

Fig. 3. Plasma $0-35 \mathrm{~h}$ triacylglycerol (TG), esterified cholesterol (EC) and free cholesterol (FC) responses to test meals in rabbits fed on a low-fat diet or fed on a high-fat, high-cholesterol diet with the fat and cholesterol components ingested by nibbling or gorging. (a,c,e), Nibbled test meals performed on week 4 with the low-fat diet $(\square)$ and on weeks $4(\triangle)$ and $8(\Delta)$ with the high-fat diet. (b,d,f), Gorged test meals performed on week 8 with the low-fat diet $(\square)$ and on weeks $4(\bigcirc)$ and $8(\bullet)$ with the high-fat diet. Results are expressed as concentration changes from post-absorptive values. Values are means for seven rabbits, with their standard errors represented by vertical bars. ${ }^{\mathrm{a}, \mathrm{b}}$ Mean values at a given time point not sharing a common letter were significantly different: $P<$ 0.05 (ANOVA for factorial non-repeated values and Fisher's test). Values for rabbits nibbling and gorging the fat-cholesterol part of the diet were significantly different at a given time point: ${ }^{\star} P<0.05$ (ANOVA for factorial non-repeated values and Fisher's test).

fatty acids/h per $\mathrm{ml}$ respectively) over the LF group while significantly higher values were found for both enzymes in the HF-G group (7.1 (SE 1.0) and 28.4 (SE 4.0) $\mu \mathrm{mol}$ free fatty acids/h per $\mathrm{ml}$ respectively).

\section{Accumulation of liver lipids}

After 8 weeks, the HF diets, as compared with the LF diet, did not induce marked changes in liver triacylglycerol contents (11.2 (SE 1.8), 9.2 (SE 1.3) and 9.4 (SE 0.7) mg/g in LF, HF-N and HF-G groups respectively). Conversely, the HF diets led to a marked 4-4.5-fold increase in liver cholesterol content as compared with the LF diet (5.0 (SE $0.5) \mathrm{mg} / \mathrm{g}$ ), which was significantly higher in the HF-G group $(25.4(\mathrm{SE} 0.9) \mathrm{mg} / \mathrm{g})$ than the HF-N group (22.3 (SE $1 \cdot 2) \mathrm{mg} / \mathrm{g}$ ).

\section{Uptake of postprandial triacylglycerol-and cholesterol-rich lipoproteins by cultured liver cells}

The time-courses of uptake of postprandial TCRL by cultured rabbit hepatocytes are shown in Table 3 . In these 

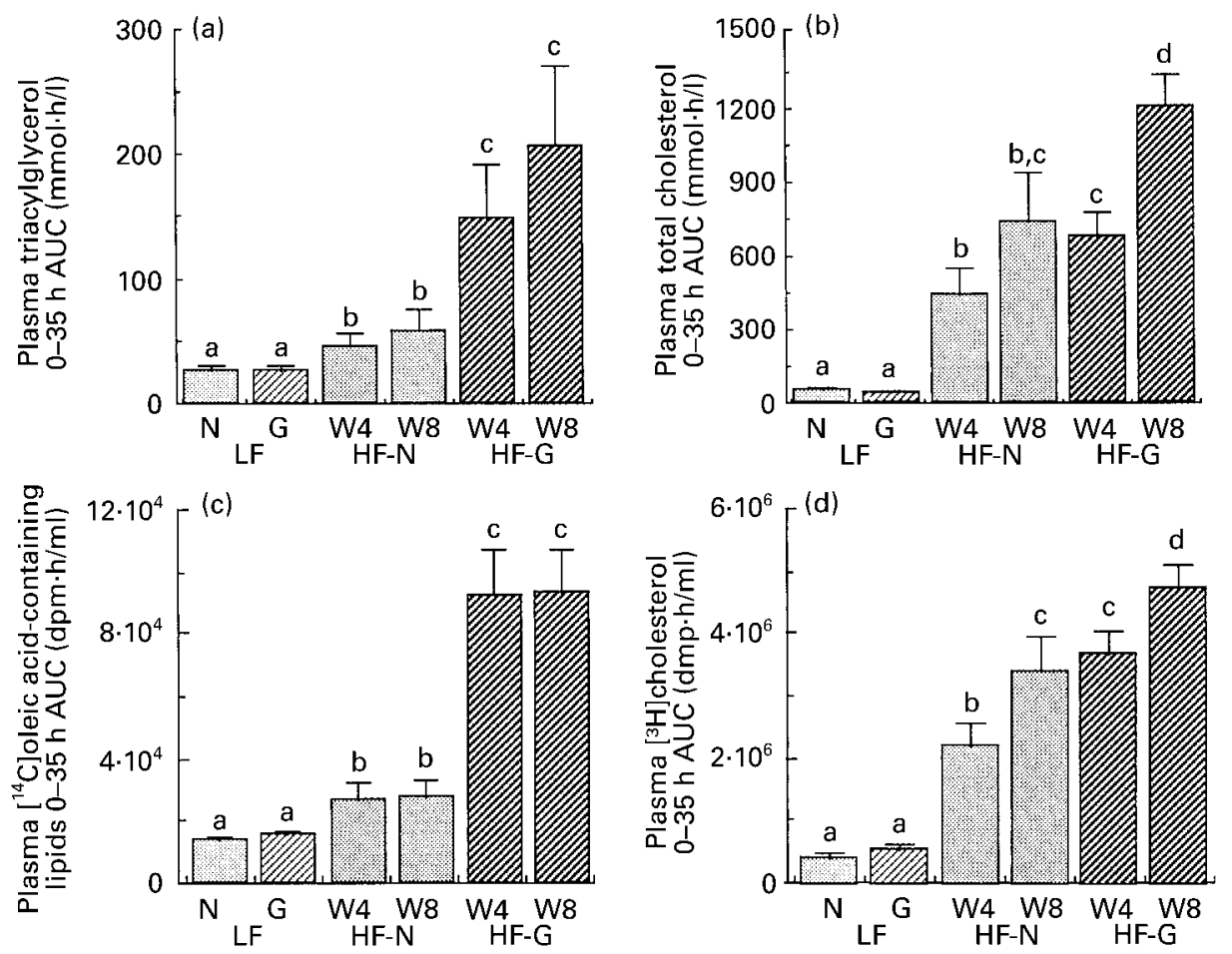

Fig. 4. The $0-35 \mathrm{~h}$ area under the curve (AUC) values for (a) triacylglycerols, (b) total cholesterol, (c) $\left[{ }^{14} \mathrm{C}\right]$ oleic acid-containing lipids and (d) $\left[{ }^{3} \mathrm{H}\right]$ cholesterol in the plasma of rabbits fed on a low-fat (LF) diet or a high-fat, high-cholesterol (HF) diet with the fat-cholesterol component ingested by nibbling $(\mathrm{N})$ or gorging $(\mathrm{G})$. Nibbled test meals were given on week (W) 4 for the LF diet and on W4 and W8 for the HF diet. Bolus (gorged) test meals were given on W8 for the LF diet and on W4 and W8 for the HF diet. Values are means for seven rabbits, with their standard errors represented by vertical bars. ${ }^{\mathrm{a}, \mathrm{b}, \mathrm{c}}$ Mean values not sharing a common letter were significantly different: $P<0.05$ (ANOVA for factorial repeated or non-repeated values and Fisher' test).

Table 3. Triacylglycerols and total cholesterol in triacylglycerol- and cholesterol-rich lipoproteins (TCRL) (\% remaining), and bile acid concentration $(\mathrm{mg} / \mathrm{l})$ in the culture medium of liver cells from rabbits fed on fat and cholesterol, after 4 and 8 or 20 incubation* $^{*}$

(Mean values with their standard errors for six donor rabbits)

\begin{tabular}{|c|c|c|c|c|}
\hline & \multicolumn{4}{|c|}{ TCRL addition $†$} \\
\hline & \multicolumn{2}{|c|}{ Simple dose } & \multicolumn{2}{|c|}{$\begin{array}{l}\text { Fractionated } \\
\text { doses }\end{array}$} \\
\hline & Mean & SE & Mean & SE \\
\hline $\begin{array}{l}\text { TCRL triacylglycerols } \\
4 \mathrm{~h} \\
8 \mathrm{~h}\end{array}$ & $\begin{array}{l}73 \cdot 6^{\mathrm{a}} \\
68 \cdot 5^{\mathrm{a}}\end{array}$ & $\begin{array}{l}3.8 \\
2.5\end{array}$ & $\begin{array}{l}57 \cdot 5^{\mathrm{b}} \\
53 \cdot 8^{\mathrm{b}}\end{array}$ & $\begin{array}{l}2 \cdot 1 \\
2 \cdot 3\end{array}$ \\
\hline $\begin{array}{l}\text { TCRL total cholesterol } \\
4 \mathrm{~h} \\
8 \mathrm{~h}\end{array}$ & $\begin{array}{l}91 \cdot 1 \\
83 \cdot 6^{a}\end{array}$ & $\begin{array}{l}1.6 \\
1.3\end{array}$ & $\begin{array}{l}86 \cdot 2 \\
74 \cdot 3^{b}\end{array}$ & $\begin{array}{l}3 \cdot 0 \\
2 \cdot 6\end{array}$ \\
\hline $\begin{array}{l}\text { Total bile acid } \\
20 \mathrm{~h}\end{array}$ & $38 \cdot 8^{a}$ & $5 \cdot 4$ & $66 \cdot 8^{b}$ & $5 \cdot 7$ \\
\hline
\end{tabular}

a,b Mean values within a row not sharing a common superscript letter were significantly different: $P<0.05$ (ANOVA for factorial non-repeated values and Fisher's test at probability of $95 \%$ ).

* Hepatocytes from rabbits that had nibbled the fat and cholesterol were incubated with postprandial TCRL from corresponding nibbling rabbits while hepatocytes from rabbits that had gorged the fat and cholestero were incubated with postprandial TCRL from gorging rabbits. As no difference was observed in TCRL uptake or bile salt secretion by the two groups, results were pooled for clarity. Equal quantities of postprandial TCRL were introduced into the medium either once (simple dose) at $0 \mathrm{~h}$ or in stepwise fractionated doses $(0.25$ total amount) at $0,1,2$ and $3 \mathrm{~h}$. For details of procedures, see pp. 550-551. experiments, HF-N rabbit hepatocytes were incubated with postprandial TCRL-N while postprandial TCRL-G were incubated with HF-G rabbit hepatocytes. As data concerning the uptake of TCRL-N or TCRL-G by respective hepatocytes did not show any difference under given incubation conditions, the pooled results are presented in Table 3. Conversely, when added once $v$. stepwise the disappearance of TCRL-N or TCRL-G triacylglycerols was significantly delayed. Concomitantly, the time course of uptake of total TCRL-cholesterol (Table 3) was different, but to a less marked extent, in the two incubation conditions.

The bile salt secretion in the culture medium was not different between $\mathrm{N}$ and $\mathrm{G}$ conditions (results not shown) and thus data obtained from HF-N and HF-G hepatocytes were pooled for clarity. As shown in Table 3, the concentration of bile salt secreted by hepatocytes after $20 \mathrm{~h}$ incubation was significantly higher in the culture medium when TCRL were added as fractionated doses as compared with a single dose.

\section{Atheroma deposition}

At the completion of the experiment ( 8 weeks), the percentage of aorta surface covered by lesions was quantified. The development of lesions was hardly detectable in rabbits from the LF group (lower level for quantification: $0 \cdot 1 \%$ of arterial surface). On the contrary, all rabbits in the HF groups developed atheromatous lesions on the aorta wall (Table 4). 
Table 4. Aortic wall areas (\% of lesioned surface) covered with atherosclerotic lesions in rabbits fed on a high-fat, high-cholesterol diet given either by nibbling (HF-N) or gorging (HF-G) for 8 weeks

(Mean values with their standard errors for seven rabbits per group)

\begin{tabular}{lccccc}
\hline & \multicolumn{2}{c}{ HF-N group } & & \multicolumn{2}{c}{ HF-G group } \\
\cline { 2 - 3 } Aorta & Mean & SE & & Mean & SE \\
\hline Thoracic & $14 \cdot 7^{\mathrm{a}}$ & 3.9 & & $26 \cdot 4^{\mathrm{b}}$ & 3.3 \\
Abdominal & $9 \cdot 4$ & $2 \cdot 6$ & & 13.9 & 3.1 \\
Total & $13 \cdot 7^{\mathrm{a}}$ & $2 \cdot 7$ & & $19.9^{\mathrm{b}}$ & 3.0 \\
\hline
\end{tabular}

a,b Mean values within a row with different superscript letters were significantly different, $P<0.05$ (ANOVA for factorial non-repeated values and Fisher's test at probability of $95 \%$ ).

Determination of the extent of lesions in the abdominal aorta did not show any significant difference between HF-N and HF-G groups. In contrast, the fraction of thoracic as well as the entire aorta surface covered by atheromatous lesions was significantly higher in the HF-G group ( 1.8 fold and 1.5 fold respectively) than in the HF-N group.

When data from HF-N $(n 7)$ and HF-G $(n 7)$ groups were analysed by regression analysis, several postprandial plasma and TCRL lipid variables were correlated with the percentage of aorta surface area covered by lesions (Table 5). No correlation was found for LDL and HDL lipids, except the plasma HDL-total cholesterol concentrations in the postprandial state $(20 \mathrm{~h})$.

\section{Discussion}

The aim of the present study was to evaluate the effects of nibbling or gorging the fat and cholesterol components of

Table 5. Correlations of postprandial plasma and lipoprotein lipid responses with atherosclerotic lesions in rabbits fed on a high-fat, high-cholesterol diet

\begin{tabular}{|c|c|c|}
\hline \multirow[b]{2}{*}{ Postprandial variables } & \multicolumn{2}{|c|}{$\begin{array}{c}\text { Aorta total } \\
\text { lesioned surface }\end{array}$} \\
\hline & $r^{2}$ & $P$ \\
\hline Plasma triacylglycerols* & 0.68 & 0.012 \\
\hline Plasma $\left[{ }^{14} \mathrm{C}\right]$ oleic acid-containing lipids & 0.76 & 0.001 \\
\hline Plasma $\left[{ }^{14}\right.$ C]oleic acid $0-35$ h AUC & 0.80 & 0.001 \\
\hline Plasma TCRL-triacylglycerols* & 0.49 & 0.075 \\
\hline Plasma TCRL $\left[{ }^{14}\right.$ C]oleic-acid ${ }^{*}$ & 0.68 & 0.008 \\
\hline Plasma LDL-triacylglycerols* & 0.38 & 0.180 \\
\hline Plasma LDL [ ${ }^{14}$ C]oleic-acid ${ }^{*}$ & 0.35 & 0.220 \\
\hline Plasma HDL-triacylglycerols* & 0.18 & 0.520 \\
\hline Plasma HDL $\left[{ }^{14}\right.$ C]oleic-acid ${ }^{*}$ & 0.49 & 0.071 \\
\hline Plasma total cholesterol* & 0.51 & 0.070 \\
\hline Plasma cholesterol 0-35h AUC & 0.99 & 0.001 \\
\hline Plasma $\left[{ }^{3} \mathrm{H}\right]$ cholesterol ${ }^{*}$ & 0.82 & 0.001 \\
\hline Plasma $\left[{ }^{3} \mathrm{H}\right]$ cholesterol $0-35$ h AUC & 0.80 & 0.001 \\
\hline Plasma TCRL-total cholesterol ${ }^{\star}$ & $0 \cdot 88$ & 0.001 \\
\hline Plasma TCRL- $\left[{ }^{3} \mathrm{H}\right]$ cholesterol* & $0 \cdot 80$ & 0.001 \\
\hline Plasma LDL-total cholesterol* & 0.36 & 0.210 \\
\hline Plasma LDL-[ $\left.{ }^{3} \mathrm{H}\right]$ cholesterol $^{*}$ & 0.35 & 0.224 \\
\hline Plasma HDL-total cholesterol* & 0.56 & 0.035 \\
\hline Plasma HDL-[ $\left.{ }^{3} \mathrm{H}\right]$ cholesterol ${ }^{*}$ & 0.49 & 0.070 \\
\hline
\end{tabular}

AUC, area under the curve; TCRL, triacylglycerol- and cholesterol-rich lipoproteins.

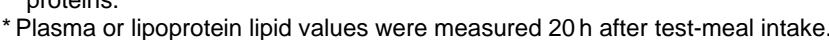

the diet in the rabbit. The daily intakes of fat and cholesterol were high but usual for this kind of study (Van Heek \& Zilversmit, 1990; Bocan et al. 1993; Daley et al. 1994a,b; Juhel et al. 1997). The two kinds of high-fat, high-cholesterol regimen were compared with a regular nibbled LF diet for 4 or 8 weeks. The postprandial effects of bolus or nibbled meals were monitored. To take into account the physiological needs of the rabbit, a natural nibbler, only fat and cholesterol were given as a bolus or not while most other nutrients were nibbled over $24 \mathrm{~h}$. Thus, this experimental design does not exactly mimic the usual human dietary patterns.

As recently reviewed (Mann, 1997), it has been shown that increasing meal frequency attenuates the postprandial response to nutrient intake and improves post-absorptive lipid variables (Jenkins et al. 1989, 1992; Arnold et al. 1993; McGrath \& Gibney, 1994) during studies performed in healthy or non-insulin-dependent diabetic human subjects. Nevertheless, these human studies were performed with diets containing low or moderate amounts of fat and the link between metabolic changes induced by nibbling $v$. gorging and progression of atherosclerosis was not evaluated. This is experimentally feasible using suitable animal models. The atherogenic nature of the postprandial state has been suggested for two decades (Zilversmit, 1979) and more recent data have established that exaggerated and/or delayed postprandial lipaemia (Weintraub et al. 1987; Miesenböck et al. 1992; Karpe et al. 1993; Lairon, 1996; Bergeron \& Havel, 1997) could be related to coronary events in man. To study more mechanisms involved, we selected the rabbit model because of its ability to develop atheroma deposition when fed on a lipid-rich diet (Bocan et al. 1993; Daley et al. 1994a,b). From the limited number of postprandial studies already performed in the rabbit (Van Heek \& Zilversmit, 1990; Juhel et al. 1997), it appeared that this species is characterized by a particularly long postprandial hypertriacylglycerolaemic response lasting about $20-30 \mathrm{~h}$ after ingestion of a bolus meal providing $6-14 \mathrm{~g}$ triacylglycerols that is primarily related to a slow rate of lipid gastric emptying (Fekete et al. 1990; Van Heek \& Zilversmit, 1990; Juhel et al. 1997). In addition, a limited clearance capacity of dietary lipids could explain this protracted postprandial event which in turn was suggested to account for the well-known outstanding capability to develop atheroma in this species (Juhel et al. 1997).

In the control group fed on a regular low-fat, cholesterolfree diet (LF diet), post-absorptive plasma lipid levels did not vary noticeably over time and a minimal postprandial response was observed irrespective of the way (gorging $v$. nibbling) the lipids were ingested, as already observed after gorging a LF meal (Juhel et al. 1997). In these animals, there was limited accumulation of dietary fatty acid-containing lipids and cholesterol postprandially. The rabbits chronically fed on this LF diet did not accumulate triacylglycerol and cholesterol moieties in the liver and had no apparent clearance defect (Mamo et al. 1991; Demacker et al. 1992) and thus, exhibited a comparable capacity to handle dietary lipids as a single bolus or a nibbled test meal. The extent of atheroma deposition in the aorta was hardly detectable in these rabbits. 
When rabbits were chronically fed on a moderately highfat $(10 \mathrm{~g} / \mathrm{d})$, high-cholesterol $(0.5 \mathrm{~g} / \mathrm{d})$ diet (HF diet), the postprandial response to the test meals was amplified as compared with the LF-fed controls, in agreement with previous observations (Juhel et al. 1997). Nevertheless, a striking observation was that the postprandial rise in triacylglycerols was significantly exacerbated in the rabbits chronically fed on the HF diet under a gorging regimen (HF-G) as compared with the nibblers (HF-N). The exacerbated post-meal hypertriacylglycerolaemic response elicited by the HF-G regimen was essentially due to a $5 \cdot 2$-fold increased concentration of TCRL-triacylglycerols in which dietary fatty acid-containing lipids and cholesterol dramatically increased (results not shown). Isolated TCRL particles are a mix of endogenous (VLDL and $\beta$-VLDL) and exogenous (chylomicrons and remnants) particles but we did not aim to make separate evaluations of their behaviour.

Although overall dietary fat and cholesterol intakes were not different in the two groups of rabbits, it appeared that rabbits who were nibbling had a less marked accumulation of TCRL in the circulation $0-35 \mathrm{~h}$ postprandially and logically, in the post-absorptive state after overnight food deprivation. This observation probably suggests that the clearance ability of the gorgers had been reduced. Several mechanisms could have contributed to the different responses observed in gorgers and nibblers.

As the existence of a nutritional adaptation of the endovascular lipases has been reported in the rabbit (Van Heek \& Zilversmit, 1990; Warren et al. 1991; Juhel et al. 1997), we checked whether the two ways of ingesting lipids would influence the enzyme levels. In the nibblers, ingesting the HF diet for 8 weeks led to a significant increase in the activities of post-heparin plasma lipoprotein lipase and hepatic lipase whereas such an adaptation occurred in the gorgers with an even more marked amplitude for both enzymes and much faster (i.e. at 4 weeks) in the case of hepatic lipase. It thus appears that repetition of lipid bolus ingestions, as compared with nibbled meals, leads to a greater nutritional adaptation of enzymes governing the plasma clearance of lipids. Nevertheless, such enhanced enzyme activities resulting from this adaptive process are unable to limit TCRL accumulation as observed in the gorgers postprandially. The saturation of lipoprotein lipase by the number and the cholesterol enrichment of TCRL particles might limit the rate of lipolysis of TCRL particles as reported in the hypercholesterolaemic rabbit (Connelly et al. 1994). Another role of these enzymes could be implicated. Both lipoprotein lipase (Mann et al. 1995; Takahashi et al. 1995) and hepatic lipase (Shafi et al. 1994; Ji et al. 1995; Karpe et al. 1996) have been shown to promote quantitatively the binding of TCRL remnants to the hepatocyte membranes via linkages to proteoglycans, thus facilitating the receptor-mediated uptake of these particles (Ji et al. 1995). In the rabbit, the hepatic lipase level is definitively low and thus, could be a limiting factor for binding and clearance even after maximal expression due to adaptation to the lipid diet. In both groups of rabbits fed with fat and cholesterol, it is possible that the relatively low level of plasma HDL could reduce normal exchanges of lipids and apoproteins and thus slow TCRL clearance (Tall et al. 1982).
A second mechanism possibly involved in the differences observed is the receptor-mediated uptake of TCRL particles by the liver. Although the TCRL fraction is heterogenous with different sub-populations of particles with possible different clearance rates, we aimed to use a global test for the hepatic uptake of TCRL particles accumulated postprandially. Thus, we investigated how cultured hepatocytes from LF, HF-N and HF-G groups of rabbits handled postprandial TCRL isolated from rabbits fed on HF-N or HF-G regimens. To mimic the postprandial state in vivo, a given amount of TCRL lipids was added once (gorging pattern) or in four portions over $3 \mathrm{~h}$ (nibbling pattern). Postprandial TCRL obtained from HF-N or HF-G groups had comparable lipid composition. Hepatocytes from HF-N or HF-G groups of rabbits had a comparably low rate of uptake of TCRL which was highly dependent on the rate of supply, i.e. a lower rate of uptake when provided as a single dose. It has already been shown that cholesterol-rich diets reduce the expression of the LDL receptor (Kovanen et al. 1981; Meijer et al. 1991), a phenomenon linked to the accumulation of free cholesterol in hepatocytes, as observed here but more markedly in HF-G than HF-N rabbit livers. Thus, this suggests that the feedback regulation of the hepatic LDL receptor could be exacerbated when a higher flux of particles enters the liver as occurring under gorging. In addition, LDL-receptor related protein could play an important role in the clearance by liver of apolipoprotein B,E-containing lipoproteins, such as $\beta$-VLDL, as suggested by studies in mice (de Faria et al. 1996), but the possible regulatory mechanisms involved are not yet clearly understood. With the hepatic receptors potentially involved, a higher flux of supply of TCRL particles is expected to exacerbate competition for binding and clearance in the space of Disse as suggested by other authors (Hussain et al. 1995). In the rabbit, extra-hepatic VLDL receptors (Takahashi et al. 1995) and bone marrow macrophages (Hussain et al. 1995) also play a role in TCRL clearance in vivo.

We observed that a single dose of TCRL as compared with a fractionated supply reduced the amounts of bile salts secreted. These data suggest that a higher flux of TCRL entering the liver might limit de novo synthesis of bile salts and thus reduce elimination of cholesterol from the liver into bile secretion. On the contrary, as shown by others in a cholesterol concentration-dependent manner (Meijer et al. 1992), the secretion of VLDL and $\beta$-VLDL by the liver in HF-G should be more pronounced than in HF-N animals. In fact, we observed such an accumulation of TCRL particles postprandially and in the post-absorptive state in the HF-G group. This TCRL fraction was enriched postprandially in dietary radiolabelled fatty acid-containing lipids (correlation with plasma triacylglycerols: $r=0.84, P=0.0001)$ and dietary cholesterol (correlation with cholesterol esters: $r=$ $0 \cdot 81, P=0.0001)$ which are probably present in the form of both intestinally-derived chylomicrons and endogenous VLDL and $\beta$-VLDL. Both kinds of particles are normally competing for lipolysis, binding and uptake by hepatic receptor pathways and the much greater postprandial accumulation in the plasma of lipid moieties of dietary origin in the gorging animals well illustrates the exacerbated competition occurring in this situation.

After 4 weeks of dietary regimen, markedly higher 
postprandial TCRL triacylglycerol and cholesterol ester concentrations were found in gorging animals as compared with nibbling ones. The two main mechanisms involved in the difference observed thus seem to be the exacerbated secretion of $\beta$-VLDL from the liver and the lowered TCRL remnant clearance in the HF-G group rabbits. It is also interesting to note that LDL-cholesterol ester concentrations were 1.6-2.7-fold higher in the gorging $v$. nibbling animals postprandially. The fact that the difference in TCRL lipid concentration tended to be less marked between gorgers and nibblers after 8 weeks leads us to suggest that the difference between the two groups would tend to be lessened with time of feeding the HF diet.

The accumulation of TCRL and their remnants (Zilversmit, 1979; Tall et al. 1982) as well as LDL enrichment in cholesterol esters (Patsch et al. 1992) in the circulation postprandially and in the post-absorptive state are seen as potentially atherogenic factors (Gianturco \& Bradley, 1994). The building of atheroma plaque on the aorta wall surface in lipid-fed rabbits has been reported previously (Daley et al. 1994a,b) as here, whereas no evident lesion development was observed in the control rabbits fed on the LF diet for 8 weeks. A worthwhile observation was that the entire extent of atheroma deposition was significantly less important $(-37 \%)$ in the nibbling animals than in the gorgers. In the New Zealand White rabbit chronically fed on a lipid-rich diet, atheromatous lesions especially accumulate in the thoracic aorta (Daley et al. 1994a,b) as observed here. The rate of atheroma deposition has already been shown to be related to exposure to $\beta$-VLDL (Daley et al. 1994b) but also to chylomicrons (Mamo \& Wheeler, 1994) that penetrate the artery wall in the same way as LDL particles, especially small dense LDL. In line with previous observations obtained in nibbling rabbits only (Juhel et al. 1997), linear regression analyses of the data obtained in both HF groups of rabbits clearly established a link between aorta lesions and triacylglycerol or cholesterol concentrations in plasma and TCRL postprandially as well as the postprandial accumulation of lipids and cholesterol of dietary origin (Table 5). These data thus support the concept that nibbling, as compared with gorging, reduces the accumulation of TCRL particles of intestinal and hepatic origin which, in turn, lowers the extent of atheroma deposition.

Considering that the overall changes in plasma lipids observed in rabbits under nibbling or gorging regimens fit well with some metabolic data obtained in human subjects in the short term (Jenkins et al. 1989, 1992), one can suggest that nibbling a fat- and cholesterol-containing diet in the long term could have less detrimental effects than gorging in human subjects. It should be emphasized that feeding the rabbit with fat and cholesterol leads to a specific accumulation of $\beta$-VLDL which does not generally occur in human beings. This hypothesis thus remains to be demonstrated in human subjects.

\section{Acknowledgements}

The authors are grateful to Diépal-Créalis (DANONE group) and Provence-Alpes-Côte d'Azur regional council for their financial support. We wish to thank M. Rivoire $(\mathrm{PhD})$ for helpful technical assistance.

\section{References}

Arnold LM, Ball MJ, Duncan AW \& Mann J (1993) Effect of isoenergetic intake of three or nine meals on plasma lipoproteins and glucose metabolism. American Journal of Clinical Nutrition 57, 446-451.

Bergeron N \& Havel RJ (1997) Assessment of postprandial lipemia: nutritional influences. Current Opinion in Lipidology 8, 43-52.

Bocan T, Mueller S, Mazur M, Uhlendorf P, Brown E \& Kieft K (1993) The relationship between the degree of dietary-induced hypercholesterolemia in the rabbit and atherosclerotic lesion formation. Atherosclerosis 102, 9-22.

Buccolo G \& David H (1973) Quantitative determination of serum triglycerides by the use of enzymes. Clinical Chemistry 19, 476-482.

Cardin AD, Witt KR, Chao J, Margolius HS, Donaldson VH \& Jackson RL (1984) Degradation of apolipoprotein B-100 of human plasma low density lipoproteins by tissue and plasma kallikreins. Journal of Biological Chemistry 259, 8522-8528.

Cohen JC, Noakes TD \& Spinnler Benade AJ (1988) Serum triglycerides responses to fatty meals: effect of meal fat content. American Journal of Clinical Nutrition 47, 825-827.

Cohn JS, McNamara JR, Cohn SD, Ordovas JM \& Schaefer EJ (1988) Postprandial plasma lipoprotein changes in human subjects of different ages. Journal of Lipid Research 29, 469-479.

Connelly P, Maguire G, Vezina C, Hegele R \& Kuksis A (1994) Kinetics of lipolysis of very low density lipoproteins by lipoprotein lipase. Journal of Biochemistry 269, 20554-20560.

Daley S, Herderick E, Cornhill J \& Rogers K (1994a) Cholesterolfed and casein-fed rabbit models of atherosclerosis. Arteriosclerosis and Thrombosis 14, 95-104.

Daley S, Klemp KF, Guyton JR \& Rogers KA (1994b) Cholesterol-fed and casein-fed rabbit models of atherosclerosis. Part 2: differing morphological severity of atherogenesis despite matched plasma cholesterol levels. Arteriosclerosis and Thrombosis 14, 105-114.

de Faria E, Fong LG, Komaromy M \& Cooper AD (1996) Relative roles of the LDL receptor, the LDL receptor-like protein, and hepatic lipase in chylomicron remnant removal by the liver. Journal of Lipid Research 37, 197-209.

Demacker P, Van Heijst P \& Stalenhoef F (1992) A study of the chylomicron metabolism in WHHL rabbits after fat loading. Journal of Biochemistry 285, 641-646.

Domingo N, Amic J \& Hauton J (1972) Dosage automatique des sels biliaires conjugués par la bile par la alpha-hydroxy-stéroide deshydrogénase (Measurement of conjugate bile salts using alpha-hydroxy-steroid deshydrogenase). Clinica Chimica Acta 37, 399-404.

Dubois C, Armand M, Mekki N, Portugal H, Pauli AM, Bernard PM, Lafont H \& Lairon D (1994) Effects of increasing amounts of dietary cholesterol on postprandial lipemia and lipoproteins in human subjects. Journal of Lipid Research 29, 469-479.

Dubois C, Beaumier G, Juhel C, Armand M, Portugal H, Pauli AM, Borel P, Latgé C \& Lairon D (1998) Effects of graded amounts $(0-50 \mathrm{~g})$ of dietary fat on postprandial lipemia and lipoproteins in normolipemic adults. American Journal of Clinical Nutrition 67, 31-38.

Fekete S, Hullàr H \& Fébel H (1990) Rabbit digestion and blood composition after fat or oil addition to the feed. Journal of Applied Rabbit Research 12, 233-238.

Gardner CD \& Kraemer HC (1996) Monounsaturated versus unsaturated dietary fat and serum lipids. A meta-analysis. Arteriosclerosis, Thrombosis and Vascular Biology 15, 1917-1927.

Gianturco SH \& Bradley WA (1994) A cellular basis for atherogenicity of triglyceride-rich lipoproteins. Atherosclerosis Review 22, 9-14. 
Groot PHE, Van Stiphout WAHJ, Krauss XH, Jansen H, van Tol A, van Ramshorst E, Chin-On S, Hofman A, Cresswell SR \& Havekes L (1991) Postprandial lipoprotein metabolism in normolipidemic men with or without coronary artery disease. Arteriosclerosis and Thrombosis 11, 653-662.

Holman RL, McGill HC \& Strong JP (1958) Technics for studying atherosclerotic lesions. Laboratory Investigation 7, 42-47.

Hussain M, Innerarity TL, Brecht WJ \& Mahley RW (1995) Chylomicron metabolism in normal, cholesterol-fed rabbits, and Watanabe heritable hyperlipidemic rabbits. Saturation of the sequestration step of the remnant clearance pathway. Journal of Biological Chemistry 270, 8578-8587.

Jenkins DJA, Ocana A, Jenkins AL, Wolever TMS, Vuksan V, Katzman L, Hollands M, Greenberg G, Corey P, Patten R, Wong G \& Josse MB (1992) Metabolic advantages of spreading the nutrient load: effects of increased meal frequency in noninsulin-dependent diabetes. American Journal of Clinical Nutrition 55, 461-467.

Jenkins DJA, Wolever TMS, Vuksan V, Brighenti F, Cunnane C, Rao AV, Jenkins AL, Buckley G, Patten R, Singer W, Corey P \& Josse MB (1989) Nibbling versus gorging: metabolic advantages of increasing meal frequency. New England Journal of Medicine 321, 929-934.

Ji ZS, Lauer SJ, Fazio S, Bensadoun A, Taylor JM \& Mahley RW (1995) Enhanced binding and uptake of remnant lipoproteins by hepatic lipase-secreting hepatoma cells in culture. Journal of Biological Chemistry 269, 13429-13436.

Juhel C, Dubois C, Senft M, Levy E, Lafont H \& Lairon D (1997) Postprandial lipaemia is exacerbated in the fat-cholesterol fed rabbit: relationship to atheroma deposition. British Journal of Nutrition 78, 301-311.

Karpe A, Ahle S, Kersting S, Hua Y, Kneser K, Nielsen M, Gliemann J \& Beisiegel U (1996) Hepatic lipase mediates the uptake of chylomicrons and $\beta$-VLDL into cells via the LDL receptor-related protein (LRP). Journal of Lipid Research 37, 926-936.

Karpe F, Bard JM, Carlson LA, Fruchart JC \& Hamsten A (1993) HDLs and alimentary lipemia. Studies in men with previous myocardial infarction at a young age. Atherosclerosis and Thrombosis 13, 11-22.

Kovanen P, Brown M, Basu S, Bilheimer D \& Goldstein J (1981) Saturation and suppression of hepatic lipoprotein receptors, a mechanism for the hypercholesterolemia of cholesterol-fed rabbits. Proceedings of the National Academy of Sciences USA 78, 1396-1400.

Lairon D (1996) Nutritional and metabolic aspects of postprandial lipemia. Reproduction Nutrition and Development 36, 345-355.

McGrath SA \& Gibney MJ (1994) The effects of altered frequency of eating on plasma lipids in free living healthy males on normal self selected diets. European Journal of Clinical Nutrition 48 , 402-407.

Mamo JCL, Bowler A, Elsegood CL \& Redgrave T (1991) Defective plasma clearance of chylomicron-like lipid emulsions in WHHL rabbits. Biochimica et Biophysica Acta 1081, 241-245.

Mamo JC \& Wheeler JR (1994) Chylomicrons and their remnants can penetrate in rabbit thoracic aorta as efficiently as smaller macromolecules, including low-density lipoprotein: high-density lipoprotein, and albumin. Coronary Artery Disease 5, 695-705.

Mann J (1997) Meal frequency and plasma lipids and lipoproteins. British Journal of Nutrition 77, S83-S90.

Mann WA, Meyer N, Weber W, Rinninger F, Greten H \& Beisiegel U (1995) Apolipoprotein E and lipoprotein lipase co-ordinately enhance binding and uptake of chylomicrons by human hepatocytes. European Journal of Clinical Investigation 25, 880-882.

Meijer GW, Beynen AC, Lovati MR, Manzoni C, van Zutphen LFM \& Sirtori CR (1991) Hyperresponsiveness to dietary cholesterol in inbred rabbits is not associated with enhanced reduction in binding of $\beta$-VLDL to liver membranes. Journal of Nutrition 122, 931-939.

Meijer GW, Van Der Palen JGP, Geelen MJH, Verluis A, Van Zutphen LFM \& Beynen AC (1992) Secretion of lipoprotein cholesterol by perfused livers from rabbits hypo- or hyperresponsive to dietary cholesterol: greater dietary cholesterolinduced secretion in hyperresponsive rabbits. Journal of Nutrition 122, 1164-1173.

Miesenböck G \& Patsch JR (1992) Postprandial hyperlipidemia: the search for the atherogenic lipoprotein. Current Opinion in Lipidology 3, 196-201.

Murphy MC, Isherwood SG, Sethi S, Gould BJ, Wright JW, Knapper JA \& Williams CM (1995) Postprandial lipid and hormone responses to meals of varying fat contents: modulatory role of lipoprotein lipase? European Journal of Clinical Nutrition 49, 579-588.

Patsch JR, Miesenboch G, Hopferwiser T, Mühlferger V \& Knapp E (1992) Metabolism and coronary artery disease. Studies in the postprandial state. Arteriosclerosis and Thrombosis 12, 13361345.

Shafi S, Brady SE, Bensadoun A \& Havel RJ (1994) Role of hepatic lipase in the uptake and processing of chylomicron remnants in rat liver. Journal of Lipid Research 35, 709-720.

Siedel J, Hagele EO, Zingenhorn J \& Wahlefeld AW (1983) Reagent for the enzymatic determination of serum total cholesterol with improved lipolytic efficiency. Clinical Chemistry 29, 1075-1080.

Takahashi S, Suzuki J, Khono M, Oida K, Tamai T, Miyabo S, Yamamoto S \& Nakai T (1995) Enhancement of the binding of triglyceride-rich lipoproteins to the very low density lipoprotein receptor by apolipoprotein $\mathrm{E}$ and lipoprotein lipase. Journal of Biological Chemistry 270, 15747-15754.

Takayama M, Itoh S, Nagasaki T \& Tanimizu I (1977) A new enzymatic method for choline containing phospholipids. Clinica Chimica Acta 79, 93-98.

Tall AR, Blum CB, Forester GP \& Nelson CA (1982) Changes in the distribution and composition of plasma high density lipoproteins after ingestion of fat. Journal of Biological Chemistry 257, 198-207.

Van Heek M \& Zilversmit DB (1990) Postprandial lipemia and lipoprotein lipase in the rabbit are modified by olive and coconut oil. Arteriosclerosis 10, 421-429.

Warren R, Ebert D, Barter P \& Mitchell A (1991) The regulation of hepatic lipase and cholesterol ester transfer protein activity in the cholesterol fed rabbit. Biochimica et Biophysica Acta 1086, 354-358.

Weintraub MS, Eisenberg S \& Breslow JL (1987) Different patterns of postprandial lipoprotein metabolism in normal, type IIa, type III, and type IV hyperlipoproteinemic individuals; effect of treatment with cholestyramine and gemfibrozil. Journal of Clinical Investigation 79, 1110-1119.

Whiting MJ, Wishart RA, Gowing MR, McManus ME \& Mackinnon AM (1989) Bile acid synthesis and secretion by rabbit hepatocytes in primary monolayer culture: comparison with rat hepatocytes. Biochimica et Biophysica Acta 1001, 176-184.

Winer BJ (1971). Statistical Principles in Experimental Design. New York, NY: McGraw-Hill.

Zilversmit DB (1979) Atherogenesis: a postprandial phenomenon. Circulation 60, 473-485. 